\title{
Acute median nerve compression neuropathy from a foreign body in the forearm
}

\author{
Chenicheri Balakrishnan MD, Jeffrey De Mercurio MD, Eti Gursel MD
}

C Balakrishnan, J De Mercurio, E Gursel. Acute median nerve compression neuropathy from a foreign body in the forearm. Can J Plast Surg 2004;12(3):147-148.

Acute compression of the median nerve in the forearm usually occurs from compartment syndrome. A case of acute compression neuropathy of the median nerve from a foreign body, where there was no evidence of compartment syndrome, is reported. The diagnosis was made from the patient's symptoms and radiographs. Early recognition and decompression of the forearm with removal of the foreign body led to full recovery.

Key Words: Acute median nerve neuropathy

\section{La neuropathie de compression aiguë du nerf médian par un corps étranger dans l'avant-bras}

D'ordinaire, la compression aiguë du nerf médian de l'avant-bras est causée par un syndrome de loge. Un cas de neuropathie de compression aiguë du nerf médian imputable à un corps étranger, sans trace de syndrome de loge, est décrit. Le diagnostic a été posé grâce aux symptômes du patient et à des radiographies. Un dépistage précoce et une décompression de l'avant-bras avec retrait du corps étranger ont permis un rétablissement total.
$\mathrm{C}$ Tompression of the median nerve usually occurs at the elbow, in the forearm or at the wrist. Although the most common site of median nerve compression is at the wrist, various etiologies have been reported for compression neuropathy of the median nerve. This includes ligamentous compression at the elbow and compartment syndrome of the forearm. Early diagnosis is usually made from history, clinical signs and radiographs. We report a case of acute median nerve neuropathy from a foreign body penetrating through the interosseous membrane.

\section{CASE PRESENTATION}

A 35-year-old man presented to the emergency department with sudden onset of severe pain in his fingers. This worsened over a period of $24 \mathrm{~h}$. He had a small laceration over the dorsal aspect of the forearm following a bar fight approximately three weeks before the onset of symptoms. His past medical history was negative for any serious illness. He had no known drug allergies and was not on any medications. He complained of tightness of the forearm, inability to extend the fingers and tingling of the fingers. Initial examination showed slight swelling of the forearm with a healed laceration over the ulnar border of the distal one-third of the forearm with fingers in a flexed position (Figures 1,2). There were limited active movements of the fingers and passive extensions of the fingers were painful. There was paraesthesia of the median nerve distribution. The two-point discrimination was prolonged on the injured side compared with the uninjured side and there was hyperesthesia over the flexor surface of the mid forearm. There were no injuries to the palm, and the dorsal and volar compartments of the forearm were soft on palpation. A clinical diagnosis of acute median nerve compression was made from clinical signs. Radiographic studies of the forearm revealed a foreign body in the forearm between the radius and ulna (Figure 3). Because there was clinical evidence of neuropathy and the radiograph confirmed the presence of a foreign body close to the median nerve, a decision was made to decompress the compartment and remove the foreign body. No attempt was made to document the compression neuropathy using an electromyogram and nerve conduction study due to the hyperesthesia of the forearm. At the time of exploration, clotted blood and a piece of a butcher's knife were found close to the median nerve. The median nerve showed no evidence of injury. Removal of the foreign body relieved the symptoms.

\section{DISCUSSION}

Compression neuropathy of the median nerve may occur at the elbow, forearm or wrist. Struther's ligament, an anomalous structure that spans between the supracondylar process in the anteromedial aspect of the humerus and the medial epicondyle, creates an arcade covering the median nerve and brachial artery. The humeral or superficial head of the pronater teres may arise from the supracondylar process and the ligament of Struthers in some instances. This ligament may produce median nerve compression (1). In the forearm, the nerve may be compressed by an increase in the intracompartmental pressure. The most common site of compression is at the wrist. When intracarpal canal interstitial pressure rises above a critical threshold pressure, capillary blood flow is reduced below the level required for median nerve viability. Median nerve compression in the forearm can occur from fractures around the wrist, spontaneous hemorrhage in 


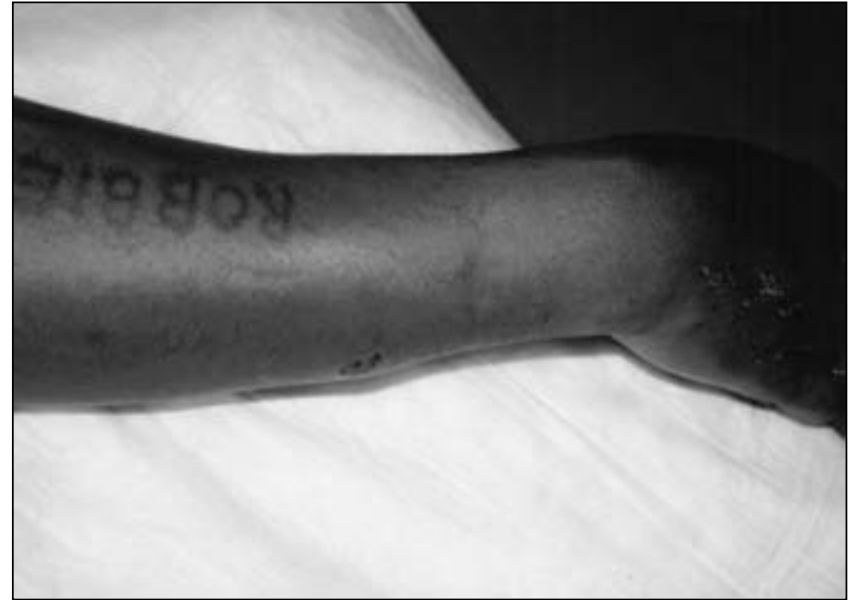

Figure 1) Healed wound over the ulnar side of the dorsum of forearm

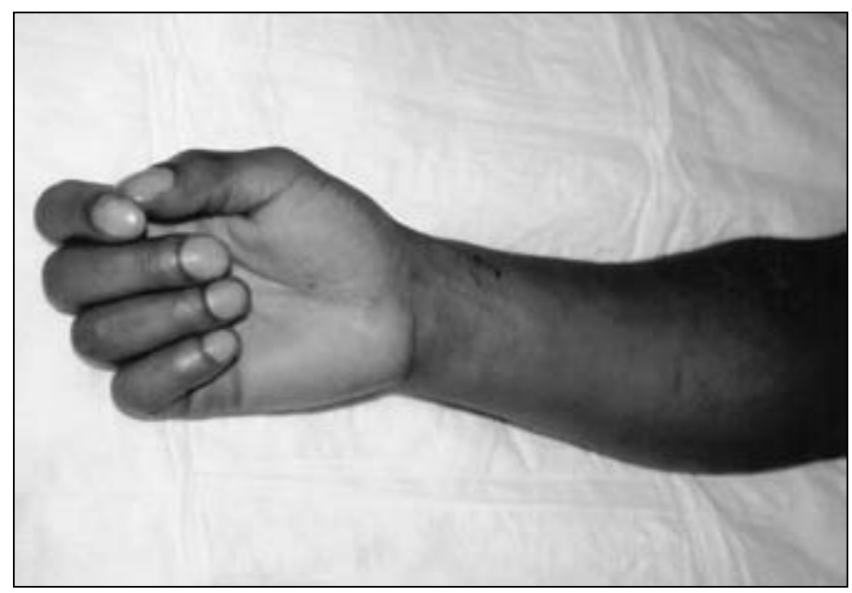

Figure 2) Fingers in flexed position

patients on anticoagulants and thrombosis of a persistent median artery (2-6). Acute carpal tunnel syndrome has been reported after a foreign body has lodged within the carpal

\section{REFERENCES}

1. Smith RV, Fischer RG. Struther's ligament: A source of median nerve compression above the elbow. J Neurosurg 1973;38:778-9.

2. Mack GR, McPherson SA, Lutz RB. Acute median neuropathy after wrist trauma. The role of emergent carpal tunnel release. Clin Orthop 1994;300:141-6.

3. Lynch AC, Lipscomb PR. The carpal tunnel syndrome and Colles' fracture. JAMA 1963;185:363-6.

4. Bonatz E, Seabol KE. Acute carpal tunnel syndrome in a patient taking Coumadin: Case report. J Trauma 1993;35:143-4.

5. Balakrishnan C, Smith FM, Puri P. Acute carpal tunnel syndrome from a thrombosed persistent median artery. J Emerg Med $1999 ; 17: 437-9$.

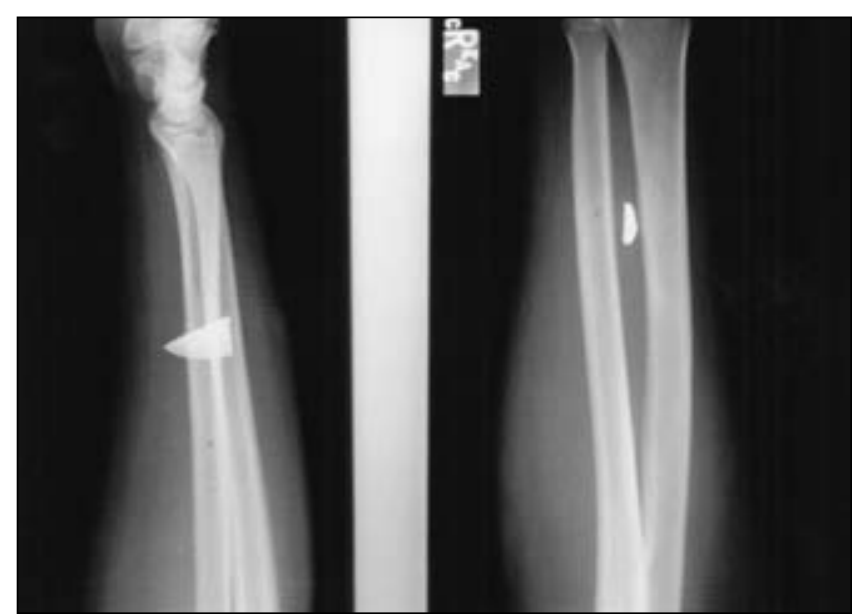

Figure 3) Radiographs showing foreign body within the forearm

tunnel $(7,8)$. This condition warrants early recognition and treatment to prevent residual nerve defect. In acute peripheral nerve compression, preoperative electrodiagnostic examination is usually recommended to confirm the diagnosis. If atypical nerve compression is suspected, magnetic resonance imaging may be indicated to detect the localized nerve compression and its underlying cause (9).

In this patient, a sudden onset of numbness in the median nerve distribution and pain in the fingers were the main symptoms. Because there was a history of trauma several weeks before presentation, and a foreign body was located by the radiograph, no electrodiagnostic studies were needed to confirm the diagnosis. Although unaware, in this patient, the foreign body entered the anterior compartment through the interosseous membrane from the laceration over the dorsal compartment. The symptoms of acute median nerve compression developed from pressure from the foreign body and possible hematoma around the nerve. This emphasizes the need for radiological examination in all penetrating wounds of the hand and vigilance in the diagnosis. Early decompression with removal of the foreign body was associated with full recovery.

6. Szabo RM. Acute carpal tunnel syndrome. Hand Clin 1998;14:419-29.

7. Sterling AP, Eshraghi A, Anderson WJ, Haberman ET. Acute carpal tunnel syndrome secondary to a foreign body within the median nerve. Bull Hosp Joint Dis 1972;33:130-4.

8. Balakrishnan C, Bradt LM, Sylora RL, Graff N. Acute carpal tunnel syndrome from a foreign body in the carpal tunnel. Can J Plast Surg 2002;10:42-3.

9. Fricker R, Fuhr P, Pippert H, Troeger H. Acute median nerve compression at the distal forearm caused by a thrombosed aneurysm of an epineurial vessel: Case report. Neurosurgery 1996;38:194-6. 